\title{
INVESTIGATION OF ALTRUISTIC VALUE PERCEPTION OF TOURISTS THAT IMPACT ON THE PRO - ENVIRONMENT BEHAVIOR
}

\author{
Öznur Bozkurt ${ }^{1}$ \\ Murat Göral' \\ Funda Kul ${ }^{3}$
}

\begin{abstract}
Environmental protection and efficient use of environmental resources is made possible by the efforts of state or other institutions to show.But take it to individual and connect to the efforts of people living in the community is also important that they show an individual.Especially environmental protection service industry in the tourism sector, which is of particular importance. One the one hand while taking advantage of the holiday in nature green act must take care to protect the environment for other generations. Altruistic values (altruism) should have to exhibit the behavior of individuals to be effective in protecting the environment were examined in this study.Pro-environmental behavior was observed that the positive effects of altruistic values. As well as to active movement within environmental behavior and have exhibited their low trend in terms of research participants take part in any organizations support. More effort is spent on an individual basis.
\end{abstract}

Key words: Altruism, Green Consumer Behaviour, Green Activistic Behaviour, Green Citizenship Behaviour,Pro- Environmental Behavior, Tourism

\section{INTRODUCTION}

Tourism (especially natural-based tourism) highly depends on environment. Tourism is particularly sensitive to environmental quality. The degradation of environmental quality of a destination (e.g. air and water pollution, environmental noise, vegetation loss and wildlife displacement) will reduce its attractiveness and competitiveness compared with other destinations, and will negatively affect its further development of tourism (Lee, Jan, \& Yang, 2013). In other words, the environment is often regarded as the major pull factor of tourist movements, contributing to the desirability and attractiveness of a tourist destination, and it is an indispensable asset to the tourism industry (Lim \& McAleer, 2005).

Protect the environment and while consumed environmental resources, which is a very important issue to think about the need for these resources in the future. In particular, the increased world population and industrialization impact on environmental pollution also this rates are increasing day by day. Institutions and organizations for the protection of the environment is a great responsibility. But it is very important for the individual to demonstrate pro-environmental behavior as to pave the way for the widespread adoption of such a culture in society. Values influence environmental behavior indirectly, via behaviorspecific beliefs, attitudes, and norms. Values may also affect the extent to which people are aware of environmental problemsassociated with their behavior (i.e., awareness of consequences). Awareness of consequenceswill increase if important environmental values are threatened, and people may adjust theirbehavior in accordance to reduce this threat.

\footnotetext{
${ }^{1}$ Assistant Professor, Faculty of Management, Düzce University, Düzce, Turkey.

${ }^{2}$ Lecturer, Social Sciences Vocational Schools, Bingöl University, Bingöl, Turkey.

${ }^{3}$ Graduated School of Düzce University, Tourism and Hotel Management, Düzce, Turkey.
} 
Many researchers (e.g., Rice, 2006; Schwartz, 1994) have examined value system in an effort to explain pro-environmental behavior. Post-materialist values typically are held by more affluent citizens who have fewer worries about the basic materials of life; they tend to be concerned with "higher-level" goals and actions such as self-improvement, personal freedom, and providing direct input to government. Among students, holding moral principles is a better predictor of environmental actions, whereas among community residents, tangible possessions (such as material economic rewards) are better predictors of environmental actions (Axelrod \& Lehman, 1993).

The aim of this study was determine whether the tourists have altruistic values and they show pro-environmental behavior. The main question of the study, determine the tourists who have altruistic perception of value the impact on the pro- environment behavior. In addition the study has sub-objectives that pro- environmental behavior whether changed according to demographics features of tourists.

\section{ALTUIRISTIC VALUE}

Relationships between values, behavior-specific beliefs, and environmental behavior have been studied extensively in social and environmental psychology (Corraliza \& Berenguer, 2000; García, et al., 2003). A large number of studies concerning values in environmental research are based on Schwartz's Value Theory (1992). Schwartz(1992) defines value as "a desirable trans-situational goal varying in importance, which serves as a guiding principle in the life of a person or other social entity". Values not only represent a society's most central cultural features (Hofstede, 2001; Schwartz, 2004) but are also fundamental factors influencing individuals' attitudes, beliefs, worldviews, norms and behaviors. The two most widely used value constructs to predict pro-environmental behaviors may be Schultz's value scale(1998) and Stern's value scale. Stern's scale has three dimensions: social-altruistic value, egoistic value and biospheric value. altruistic values prescribe that adverse consequences are likely to occur to others and that an individual can, by the appropriate action, prevent or ameliorate those consequences (Stern \& Dietz, 1994) Some studies about pro-social behavior have not supported a distinction between biospheric and altruistic values; But Han(2015) cites that is generally believed to be effective to differentiate altruistic from biospheric value orientations (De Groot \& Steg, 2007; Klockner, 2013). Since the ecological problems are more visible in recent years, a separate biospheric value is emerging and considered to be a critical aspect of value in explicating one's pro-environmental decision-making process and behavior. Altruistic value in that altruistic behaviors are based on the perceived benefits and costs to others. Altruistic values are exhibited when someone makes an environmental decision based on the benefits/costs to others, as opposed to oneself, whether the decision involves the society. ( Lee at al., 2014).

Based on prior research, we explore the role of altruistic value in predicting proenvironmental behavior. We assume people with altruistic orientation care about other people and species and, therefore, they are more likely to engage in activities that will help protect or preserve the environment than those with less altruistic orientation (Schultz et al., 2005). Thus, we anticipate a positive relationship between altruistic value orientation and the pro environmental behavior. 


\section{PRO - ENVIRONMENTAL BEHAVİOR}

Many studies on environmental behavior have been conducted without carefully defining environmental behavior. Often environmental behavior is assumed to be an undifferentiated class of behaviors (Stern, 2000). By doing so, it is implicitly assumed that various types of environmental behavior are dependent on similar factors, which is not always the case (Stern et al).

In using the term pro-environmental behaviour, we are not implying that the behaviour has a positive benefit on the environment, but rather that it has less of a negative impact than an alternative behaviour. We question whether such measures are meaningful given the likely heterogeneity between behavioural dimensions of the extent to which an individual's behaviour tends to be proenvironmental. We evaluate whether a simple sum of behavioural indicators from multiple dimensions provides a good summary measure of the extent to which a person tends to act in an pro- environmental way. We do this by comparing it to an empirically-derived weighted sum with respect to an internal validity criterion. Furthermore, we assess the extent to which such measures explain the overall variability in behaviour across a range of relevant behaviours. The solutions about environmental issues have been producing and increasing day by day (Çabuk et al, 2003; 41). Formerly, environmentalism means protection of nature and natural life, nowadays; it means a range of activities which is supported wide masses and including more fields and meaning (Baydaş, et al, 2000;468).

Pro environmental behavior is such behavior which is generally (or according to knowledge of environmental science) judged in the context of the considered society as a protective way of environmental behavior or a tribute to the healthy environment. Environmentally protective option is to write a letter by handwriting instead of using a computer, a tribute to the healthy environment is e.g. a disposal of illegal dumping .The following terms can be used as equivalents for pro environmental behavior "environmentprotective behavior" , "environment-preserving behavior", "environmentally responsible behavior"( Kaiser et al., 1999). To be exact, people are likely to become engaged in proenvironmental behaviors to the extent that environmental problems have threatened various objects they value, and they are aware of the harmful impacts (Stern and Dietsz, 1994).

Term "green" is typically used interchangeably with pro-environmental. However, because of differences in definitions of environment, the term is necessarily imprecise. We use term "green" simply to indicate concern with physical environment (air, water, land) (Schrum,1995). Green purchasing is to prefer purchasing green product to others (Schrum, 1995). In general, green product is known as an ecological product or eco-friendly product. It is defined green product as the product that will not pollute the earth or deplore natural resources, and can be recycled or conserved. It is a product that has more environmentally sound content or packaging in reducing the environmental impact. In other words, green product refers to product that incorporates the strategies in recycling or with recycled content, reduced packaging or using less toxic materials to reduce the impact on the natural environment (Chen \& Choi, 2010)

Autio \& Heinonen $(2004,138)$ added ethic term in green purchasing literature and stated firstly, consciousness of environmental problems and social injustice, and secondly, a degree of self-discipline and desire for knowledge. Thirdly, the consumer must believe that an individual person can make a difference in the struggle against environmental degradation through private consumption habits. Responsible consumers, who aim at 
lowering their level of personal consumption or even buying fairtrade products, need information to play an active role as consumers.

Unlike green purchase behavior which is limited to purchase of a green product, good citizenship behavior is viewed in this study as a non-purchase-related activity to have a positive impact on the environment. Examples may include participation in recycling and taking part in a community clean-up drive. Good citizenship behavior seems to have a more direct effect on the preservation or protection of the environment than green purchase behavior because the effect of green purchase is not usually materialized through the purchaser but through the business processes and practices employed by manufacturers and their suppliers. One of the discerning characteristics that separate green purchase behavior from good citizenship behavior may be their underlying motives. While purchasing of a green product may be motivated by both personal (e.g., purchasing and consuming organic produce for personal health) and public reasons (e.g., purchasing an eco-friendly product in order to support the pro- environmental business), the motive for engaging in good citizenship behavior is usually rooted in the public reasons. For example, making efforts to avoid using aerosol spray cans can be costly to the person due to the inconvenience associated with search and purchase of an alternative.

A person engaging in this behavior bases his decision on the potential benefits for the environment and the society. Thus, we view good citizenship behavior as a purer and more active form of pro-environmental behavior than green purchase behavior because it requires some extent of personal cost or sacrifice and has a more direct effect on environmental protection or preservation (Lee et al, 2014).

The final dimension of pro-environmental behavior is environmental activist behavior. Environmental activism has been defined as a function of specific behaviors. Examples of activists' behaviors include the following: being part of environmentalist movement (Herrera,1992; Walsh\& Warland, 1983);taking action on a particular environmental problem or conservation issue; identifying strongly with a social group; signing a petition or donation Money to a group; being committed to solve environmental problems; being an active member of an environmental organisations (Edwards \&Oskamp,1992). In majority of cases, environmental activism is defined as function of associations of an environmental organization (Segun et al, 1998).

Activists have a number of tactical weapons in their arsenal. Some tactics, such as civil suits, may impose a direct financial obligation on the firm if successful, not to mention the time and effort necessary defending oneself in court. Others, like protests, boycotts, and letter writing campaigns may impact consumers' willingness to pay for firm products and services and impact stock market valuations of the firm (Pruitt \& Friedman, 1986)

Because environmental activist behavior is concerned with actions that are aimed at making changes at the institutional level through political process, rather than at the individual level, we view this as the most collective form of behavioral solutions to the environmental problems. We believe all these three types of pro-environmental behavior have a common effect, that is, to have a positive influence on the environment. While these three types of behavior may be related to each other, and thus, discerning one from the others may be challenging, we believe that an attempt to categorize the behaviors and examine their antecedents will be helpful for advancing our knowledge in this field (Lee et al, 2014). 


\section{PURPOSE AND IMPORTANCE OF STUDY}

The altruistic value perception of the main objectives of the research was to determine the impact of tourists on pro-environmental behavior. First of all, they have been investigated as a priority to pro-environmental behavior altruistic values and perceptions of those surveyed and after altruistic perception of value has been determined that affect proenvironmental behavior. Also studied the diversity of environmental behavior in terms of demographic characteristics. Environmental protection and efficient use of environmental resources will be faced in the coming years are very important for the prevention of severe environmental damage. State government and individuals will have to treat sensitive for protect the environment. In this study, the environmental behavior of altruistic values were based on the assumption of a positive impact.Emphasizing the importance of altruistic values and perceptions of individuals concerted effort to be placed in the family and school either this perception is emphasized.

\section{METHOD}

Tourists altruistic value perception of pro-environmental behavior conducted this study to determine the impact of quantitative research methods were used in survey techniques. Düzce of Akçakoca district were collected by 110 tourists who visited easily from the sampling method. There are eight questions on the scale that measures the value of altruistic. These questions are taken from a study conducted by Stem and others(1994). 13 questions that measure pro- environmental behavior is taken from a study conducted in 2014 by Lee.Question 8 has also been added to determine the demographic characteristics of survey participants. The reliability and validity of the scale was examined by three academics.It conducted a pilot study on 30 people after application.It made the final analysis the scale reliability coefficient alpha's pro- environmental behavior $81 \%$, while the altruistic values were $91 \%$.basic statistics analyzed by SPSS 18 program in order to identify research questions after this analysis was conducted.

\section{FINDINGS}

\section{Demographic Characteristics of Participants}

Demographic characteristics of the respondents in the survey are as follows. $38 \%$ are over the age of $35,61 \%$ were married, $68 \%$ were male, $86 \%$ is composed of graduate and postgraduate degree. $62 \%$ have get over 2000 TL $60 \%$ work in public and $30 \%$ work in the private sector, $10 \%$ are unemployed. The majority live in cities and the most common leisure travels weekly then as they do daily.

\section{The Altruistic Value Perceptions of Participants Research}

There are eight questions, prepared to measure the altruistic values. The responses of those surveyed are as follows. Does not matter a farthing, It's not important, Neither important nor unimportant, Important, Very important 
Tab. 1. Altruism Value

\begin{tabular}{|c|c|c|c|c|c|c|}
\hline Altruistic Value Variables & 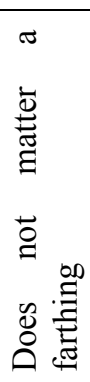 & 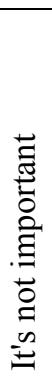 & 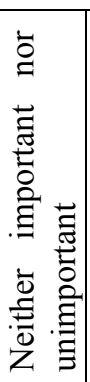 & 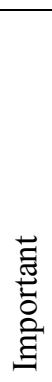 & 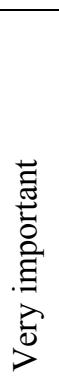 & $\sum_{\Sigma}^{\Xi}$ \\
\hline $\begin{array}{l}\text { Adaptation to the environment (people, } \\
\text { buildings, production, consumption, etc.) }\end{array}$ & & & & & & \\
\hline Environmental protection & & & & & & \\
\hline Prevention of environmental pollution & & & & & & \\
\hline $\begin{array}{l}\text { Respect the Earth (pollution, conservation, } \\
\text { save, development, etc.) }\end{array}$ & & & & & & \\
\hline World peace & & & & & & \\
\hline $\begin{array}{l}\text { Social justice (in the standard of living of the } \\
\text { different segments of society, the balance of } \\
\text { income subject) }\end{array}$ & & & & & & \\
\hline Helpfulness & & & & & & \\
\hline $\begin{array}{l}\text { Equality (equal sharing of resources, equal } \\
\text { responsibility to protect, etc.) }\end{array}$ & & & & & & \\
\hline
\end{tabular}

Research shows that the respondents have altruistic value perception in general. The highest trend is that world peace is very important. This charity is pursuing helpfulness,social justice and environmental protection. 


\section{Environmentally Behavior Trends of Participants}

Pro-environmental behavior consists of green consumer behaviour,green activistic behaviour, green citizenship behaviour. General trends for these variables is as follows.

Tab. 2. Pro-Environmental Behavior

\begin{tabular}{|l|c|}
\hline Environmentally Behavior Variable(3.74) & Mean \\
\hline Green Consumer Behaviour & 3.90 \\
\hline Green Activistic Behaviour & 3.13 \\
\hline Green Citizenship Behaviour & 4.17 \\
\hline
\end{tabular}

Study participants exhibit po-environmental behavior. tendency to become responsible citizens is highest. The lowest average size is about the act of actively.

\section{Altruistic Value Impact on Pro- Environmental Behavior}

The following table related regression, about altruistic values of tourists impact on proenvironmental behavior

Tab. 3. Effect of Altruism on Pro-Environmentally Behavior

\begin{tabular}{|c|c|c|c|c|c|c|}
\hline \multicolumn{7}{|c|}{ Coefficients $^{\mathrm{a}}$} \\
\hline \multirow{2}{*}{\multicolumn{2}{|c|}{ Model }} & \multicolumn{2}{|c|}{ Unstandardized Coefficients } & \multirow{2}{*}{\begin{tabular}{|l|} 
Standardized \\
Coefficients \\
Beta
\end{tabular}} & \multirow[b]{2}{*}{$\mathrm{t}$} & \multirow[b]{2}{*}{ Sig. } \\
\hline & & $\mathrm{B}$ & Std. Error & & & \\
\hline \multirow[t]{2}{*}{1} & (Constant) & ,137 &, 521 & & ,264 &, 792 \\
\hline & Altruism & ,780 &, 112 &, 556 & 6,946 &, 000 \\
\hline
\end{tabular}

According to regression analysis altruistic values affects demonstrate environmental behavior $(\mathrm{P}=000<.05)$. This was the main question of the research and it turned out as expected.The value of this altruistic effect is positive. These results demonstrated the need to focus on the altruistic value which placed society.

\section{RESULT AND DISCUSSION}

Conducted to examine the effect of the tourists perception of altruistic values in proenvironmental behavior over altruistic values to act according to the results of this study are a positive influence on environmentalists. To create environmental awareness in the community to that effect and should contribute to the preservation of environmental resources. Protection of environmental resources consumed or damaged every day for various reasons is a major issue. Pro- environmental behavior, which is a multidisciplinary subjects in this study were examined individually. tourists altruistic values and perceptions of trends in environmental behavior were examined. those surveyed were higher perception of altruistic values and behaviors it has been shown to exhibit green. 
To compare these results with literature or common belief the following studies results are to be presented. Cameron, Brown \& Chapman (1998) concluded that altruistic value orientation may lead to differences in environmental behaviors, primarily because of differences in perceptions of the personal costs incurred from engaging in these behaviors. This result is similar to (Garling et al, 2003) concluded that altruistic consequences were more and egoistic consequences less salient. However, according to Joireman et al ' study results (2001): egoistic expressed stronger pro-environmental intentions and stronger belief in the social consequences of environmental conditions.

Environmental behavior showed actively involved in an organization or an organization supporting the trends are lower. namely in terms of showing unity as individual attention on environmental protection of research participants are showing positive behavior. exhibit altruistic behavior trends indicate any difference in terms of gender differences in terms of demographic characteristics. women tend to have more green behavior than men. As a result of this work should be related both to individuals and organizations in the community who are advised to work to protect the environment. And also made a small resort in the area that has less environmental pollution in this study is recommended for areas that have more environmental pollution. by region and thus preferred environmentalists determined that the differences in altruistic behavior. also advised to research will take place in the cultural factors that affect pro- environmental behavior, the researchers will be working in this field.

\section{REFERENCES}

1. Axelrod, L. J., \& Lehman, D. R. (1993). Responding to environmental concerns: What factors guide individual action? Journal of Environmental Psychology, 13, 149-159

2. Autio, M., \& Heinonen V. (2004). Toconsumeor not to Consume? Young People's Environmentalism in the Affluent Finnish Society, Young, 12(2):137-153.

3. Baydaş, A., A.Tan, H. Ç. Bedestenci (2000): "Consumer and Environmental Consciousness - A Case of the Kahramanmaraş "5th National Marketing Congress, Antalya, 16 - 18 Kasim 2000, $467-485$.

4. Cameron, L. D., Brown, P.M., \& Chapman, J. G. (1998). Social value orientations and decision to take proenvironmental action. Journal of Applied Social Psychology, 28(8), 675-697.

5. Chen, T. B. \& Chai L.T. (2010). Attitude Towards the Environment and Green Products: Consumers' Perspective, Management Science and Engineering, 4(2): 27-39

6. Corraliza, J. A., \& Berenguer, J. (2000). Environmental values, beliefs, and actions. A situational approach. Environment and Behavior, 32, 832-84.

7. Çabuk, Serap, M. Burak Nakıboğlu (2003): "Environmental marketing and an application related to effects on consumer buying behavior of environmental attitudes, Çukurova University Institute of Social Sciences Journal, 12, 12, 39-54.

8. De Groot, J. I. M., Steg, L., \& Dicke, M. (2007). Morality and reducing car use: testing the norm activation model of prosocial behavior. In F. Columbus (Ed.), Transportation research trends. New York, NY: NOVA Publishers.

9. Edwards, T.C. \& Oskamp, S. (1992). Compenents of antinuclear war activism. Basic and Apllied Social Psychology, 13, 217-230.

10. García Mira, R., Real Deus, E., Durán Rodríguez, M., \& Romay Martínez, J. (2003). Predicting environmental attitudes and behavior. In G. Moser, E. Pol, Y. Bernard, M. Bonnes, J. A. Corraliza, \& M. V. Giuliani (Eds.), People, places and sustainability. Seattle, WA: Hogrefe \& Huber 
11. Gärling, T., Fujii, S., Gärling, A., \& Jakobsson, C. (2003). Moderating effects of social value orientation on determinants of proenvironmental behavior intention. Journal of Environmental Psychology, 23(1), 1-9.

12. Han (2015). Travelers' pro-environmental behavior in a green lodging context: Converging value-belief-norm theory and the theory of planned behavior,Tourism Management 47, 164- 177

13. Herrera, M. (1992). Environmentalism and political participation: Toward a new system of social beliefs and values ?, Journal of Applied Social Psychology,22, 657-676.

14. Hofstede, G. (2001). Culture's consequences: Comparing values, behaviors, institutions and organizations across nations (2nd ed.). Thousand Oaks, CA: Sage.

15. Joireman, J., Lasane, T. P., Bennet, J., Richards, D., \& Solaimani, S. (2001). Integrating social value orientation and the consideration of future consequences within the extended norm activation model of proenvironmental behaviour. British Journal of Social Psychology, 40(1), 133-155.

16. Kaiser, , Florian G., et al.(1999). Ecological Behavior, Environmental Attitude, and Feelings of Responsibility for the Environment. European Psychologist. 1999, vol. 4, 2, $59-74$.

17. Klockner, C. A. (2013). A comprehensive model of the psychology of environmental behavior - a meta-analysis. Global Environmental Change, 23, 1028-1038

18. Lee,Y., Kim, S., Kim, M. \&Choi, J.(2014). Antecedents and interrelationships of three types of pro-environmental behavior

19. Lee, T. H., Jan, F.-H., \& Yang, C.-C. (2013). Conceptualizing and measuring environmentally responsible behaviors from the perspective of community-based tourists. Tourism Management, 36, 454-468.

20. Lim, C., \& McAleer, M. (2005). Ecologically sustainable tourism management. Environmental Modelling \& Software, 20(11), 1431-1438

21. Pruitt, S.W. \& M. Friedman, (1986) Determining the Effectiveness of Consumer Boycotts: A Stock Price Analysis of Their Impact on Corporate Targets, Journal of Consumer Policy, 9(4), 375-387.

22. Rice, G. (2006). Pro-environmental behavior in Egypt: Is there a role for Islamic environmental ethics? Journal of Business Ethics, 65(4), 373-390.

23. Schultz, P. W., \& Zelezny, L. C. (1998). Values and proenvironmental behavior: A fivecountry survey. Journal of Cross-Cultural Psychology, 29(4), 540-558.

24. Schultz, P. W., Gouveia, V. V., Cameron, L. D., Tankha, G., Schmuck, P., \& Frane k, M. (2005). Values and their relationship to environmental concern and conservation behavior. Journal of Cross-Cultural Psychology, 36, 457-475.

25. Schwartz, S. H. (1992). Universals in the content and structure of values: Theoretical advances and empirical tests in 20 countries. In M. Zanna (Ed.), Advances in experimental social psychology. Orlando, FL: Academic Press.

26. Schwartz, S. H. (2004). Mapping and interpreting cultural differences around the world. In H. Vinken,

27. J. Soeters, \& P. Ester (Eds.), Comparing cultures, dimensions of culture in a comparative perspective ( 43- 73). Leiden, the Netherlands: Brill.

28. Seguin, C.,Pelletier, L. G. \& Hunsley, J. (1998). Toward a model of environmental activism, Environment and Behavior, 30, 628-652.

29. Shrum, L. J., McCarty J.A. \& Lowrey T.M. (1995). Buyer Characteristics of the Green Consumer and Their Implications for Advertising Strategy, Journal of Advertising, 14(2): 71-82.

30. Stern, P. C. (2000). Towards a coherent theory of environmentally significant behavior. Journal of Social Issues, 56(3), 407-424.

31. Stern, P. C., \& Dietz, T. (1994). The value basis of environmental concern. Journal of Social Issues, 50(3), 65- 84 
32. Stern, P. C., Dietz, T., Ruttan, V. W., Socolow, R. H., \& Sweeney, J. L. (Eds.). (1997). Environmentally significant consumption. Washington, DC: National Academy Press.

33. Walsh, E. J.,\& Warland, R. H. (1983). Social movement involvement in wake of nuclear accident: Activists and free riders in the TMI area. Ameriacan Sociological Review, 48, 746-780. 